\title{
AS CANÇÕES DE VINEGAR TOM: UMA RELEITURA CONTEMPORÂNEA DA MÚSICA NA OBRA DE BRECHT ${ }^{1}$
}

\author{
Dr $^{\mathrm{a}}$. Maria Brígida de Miranda², Cláudia Mussi ${ }^{3}$
}

PALAVRAS-CHAVE: Vinegar Tom, música, teatro feminista, Bertolt Brecht

RESUMO: Este artigo pretende investigar como a banda do espetáculo Vinegar Tom pode ser interpretada como uma releitura das encenações de canções na obra de Bertolt Brecht. Disserta sobre a proximidade deste formato de estrutura cênica com o público contemporâneo e expõe as principais características da peça montada pela diretora Dr ${ }^{\mathrm{a}}$. Brígida Miranda para as disciplinas Montagem Teatral I e Montagem Teatral II do curso de Artes Cênicas da UDESC nos anos de 2007 e 2008.

O espetáculo Vinegar Tom (Caryl Churchill, 1976) teve sua primeira montagem no Brasil, com tradução inédita, no curso de Artes Cênicas da Universidade do Estado de Santa Catarina (UDESC), com caráter curricular. Foi encenado pela professora Dra Maria Brígida de Miranda nas disciplinas Montagem I e Montagem II, acontecendo, respectivamente, nos semestres 2007.2 e 2008.1. Enquanto que no Brasil nunca haviam sido encenadas obras da dramaturga inglesa Caryl Churchill, nos países de língua inglesa, a autora é muito reconhecida: em universidades dos Estados Unidos, por exemplo, Vinegar Tom já foi encenado mais de dez vezes ${ }^{4}$, além das montagens na Austrália ${ }^{5}$, Nova Zelândia ${ }^{6}$ da montagem original inglesa (1978).

Durante a montagem de Vinegar Tom, atuei como diretora musical. Este trabalho aconteceu em conexão, como uma pesquisa de campo na área de prática teatral, às pesquisas de teatro e gênero que venho desenvolvendo como bolsista de iniciação científica no Centro de Artes da UDESC. Durante este período, a prática e a teoria

\footnotetext{
${ }^{1}$ Este artigo é o resultado da pesquisa Poéticas do Feminino e Masculino: a prática teatral sob a perspectiva das teorias de gênero, desenvolvido no Centro de Artes (CEART/UDESC).

${ }^{2}$ Orientadora, professora do Departamento de Artes Cênicas - CEART/UDESC.

${ }^{3}$ Graduanda do curso de Artes Cênicas. Bolsista de Iniciação Científica pelo PROBIC/UDESC.

${ }^{4}$ Buttler University (Indianópolis, IN); Denver University (Denver, CO); Illinois State University (Normal, IL); Portland State University (Portland, OR); Sacramento State University (Sacramento, CA); Tisch School of the Arts (New York, NY); University of Pittsburgh (Pittsburgh, PA); University of Puget Sound (Tacoma, WA); Washington University (St. Louis, MO) e West Virginia University (Morgantown, WV).

${ }^{5}$ Pela Australian Academy of Dramatic Art, sob direção de Andrew Davidson, s/d.

${ }^{6}$ Pelo New Zealand College Of Performing Arts Productions, sob direção de Richard Finn, 2001.
} 
caminharam em comunhão para que não apenas se abrisse espaço nos palcos do Brasil para a reflexão das questões de gênero, mas também para que se produzisse conhecimento a partir destas práticas e sobre elas. Neste artigo, apresento a pesquisa a que me dediquei nos meses de montagem de Vinegar Tom, em que descobri as diferentes possibilidades para a encenação das canções da peça - possibilidades, estas, que nortearam minha pesquisa prática enquanto diretora musical do espetáculo.

Vinegar Tom conta a história da caça às bruxas na Essex (Inglaterra) do século XVII sob uma ótica feminista. O fazendeiro Jack e sua esposa Margery prosperam economicamente enquanto seu casamento segue em direção oposta. Jack se sente atraído por Alice, sua vizinha. A garota é filha de Joan Noakes, uma viúva que vive fora dos códigos morais: não freqüenta a paróquia e gosta de fermentar cerveja para seu consumo. Jack e Margery concluem que seus problemas são causados pela velha Noakes, que, segundo eles, lança bruxarias em suas propriedades. Quando um caçador de bruxas (Henry Packer) e sua assistente (Goody Haskins) chegam à cidade, Noakes, Alice, Ellen (uma mulher que detém sabedoria sobre ervas e medicamentos naturais) e Susan (amiga de Alice que já passou por dois abortos) são acusadas como bruxas e enforcadas em praça pública.

Nas palavras da autora, Vinegar Tom é "uma peça sobre bruxas, mas sem bruxas nela; não é uma peça sobre o mal, histeria e possessão pelo diabo, mas sobre pobreza, humilhação e preconceito, e sobre como as mulheres acusadas de bruxaria viam a si mesmas $^{7}$ " (1982:67). Ou seja, a peça declaradamente feminista se utiliza do ambiente de caça às bruxas na Inglaterra da Idade Média para falar ao espectador de hoje sobre questões relacionadas à mulher que ainda vigem e são relevantes. O comportamento social esperado das mulheres, o aborto, a histeria, os problemas matrimoniais, a falta de liberdade de expressão, a menstruação, a menopausa e a velhice são temas recorrentes em Vinegar Tom.

Churchill optou por escrever a peça sob a ótica do Teatro Épico de Bertolt Brecht. A ação dramática é historicizada e pretende que o espectador tenha um olhar crítico sobre os acontecimentos e que não pense a respeito do espetáculo apenas como um recorte da história. A estrutura da sucessão de cenas é episódica, em que cada uma é isolada da outra e possui um clímax próprio. Esta estrutura pretende, também, que o

\footnotetext{
${ }^{7}$ As traduções de citações neste artigo foram feitas pela autora.
} 
espectador tenha tempo de inserir seu julgamento, para que então seja despertada uma consciência crítica para os contextos atuais da realidade social e política em que se observam falhas. Como mostra Janelle Reinelt:

\begin{abstract}
Vinegar Tom incorpora uma análise feminista-socialista para atacar o problema do relacionamento entre gênero e classe. Usando a noção de historicizar a narrativa, a peça coloca a sexualidade dentro da história das bruxas e da bruxaria, problematizando a interpretação tradicional daquela história e apontando para os vestígios remanescentes deste pensamento na vida contemporânea (1990: 156)
\end{abstract}

Talvez a maior arma brechtiana que Churchill usou em Vinegar Tom tenham sido as sete canções que inseriu no decorrer da peça para entrecortar a ação e fazer comentários musicais sobre as cenas para a platéia. "Críticos concordam que a mensagem feminista da peça está centralizada nas músicas; sem elas, a peça é apenas um drama histórico sobre os julgamentos de bruxas em Essex no século dezessete", afirma Neblett (2003:101). Gillian Hanna, atriz que interpretou Alice na montagem original, defende as canções contra objeções de alguns críticos que sentiram que elas eram desnecessárias:

Nós tínhamos um sentimento muito forte de que não queríamos permitir que a audiência perdesse a responsabilidade por ver um pedaço de um período, um pedaço interessante de história. Eu acredito que apenas mostrar um conto historicamente, por exemplo, não é suficiente (...). Nossa experiência é que a vida não é a história simples e que você tem que achar alguma forma de reconhecer isso na forma dramática (HANNA apud REINELT 1990:157)

A autora não deixa claro por meio de rubricas como as canções devem ser encenadas, nem é mostrado como foi feito originalmente. Há apenas uma indicação no script: “A peça se passa em torno de uma pequena vila durante o período de algumas semanas, no século XVII. As canções se passam no presente”. Apenas na edição de Vinegar Tom publicada pela Samuel French, há uma nota da autora a respeito da encenação das músicas: “As canções, que são contemporâneas, devem, se possível, ser cantadas por atores em figurinos modernos. Elas não são parte da ação e não são cantadas pelas personagens presentes na cena anterior à música.” (1982:69). Segundo a análise de Neblett, esta carta pode ter sido "uma resposta para duas produções americanas que apresentaram a peça mais ou menos como um teatro musical tradicional e não com uma 'brincadeira musical' brechtiana” (2003:105). A música em Brecht tem uma função diferente da música no teatro musical americano e na ópera. 
A música e a lírica nas obras de Brecht (recurso cênico musical) assumem a função de comentar os textos, de tomar posição em face dele e acrescentarlhe novos horizontes. Não intensifica a ação; neutraliza-lhe a força encantatória, distanciando através da quebra de um fluxo dramático em andamento. (FURTADO, 2005: s/p)

Na montagem original, os atores eram também cantores. Isto possibilitou que eles mesmos cantassem as músicas apenas trocando de figurino e entrando em cena fora das personagens, representando figuras contemporâneas. A respeito dos arranjos, realizados por Helen Glavin e Josefina Cupido, Neblett faz o seguinte comentário:

\begin{abstract}
A instrumentação é simples: as partituras pedem por um piano, um violão e congas. Esse arranjo particular de teclado, cordas e percussão tem o potencial de ser altamente versátil na sua capacidade de apresentar vários estilos musicais distintos. A composição é caracteristicamente acústica e lembra muitas bandas populares de folk do início até a metade da década de 1970, representando em termos musicais o clima do ativismo feminista de Caryl Churchill. (2003:112)
\end{abstract}

Na montagem brasileira, a idéia da diretora para a encenação das canções era que houvesse em palco uma banda de rock composta apenas por mulheres. Para Miranda, esta proposta era uma forma de criar um discurso jovem, que pudesse dialogar com o público ao mesmo tempo em que proferisse um discurso feminista por meio das letras. Outro aspecto interessante, que a diretora pretendia realçar, é que o rock é um ambiente tipicamente masculino; mulheres habitando este espaço já seria uma subversão a este princípio. Para tanto, foram poucas as intervenções da direção no processo criativo da banda.

Apesar de as montagens das obras de Brecht geralmente utilizarem um formato de encenação de músicas semelhante ao da montagem original de Vinegar Tom ${ }^{8}$, em que os atores interpretam as músicas, não se pode dizer que uma banda de rock em palco dividindo o espaço com os atores divirja deste pensamento. Sabe-se que nas encenações de Brecht o contato com o público era muito importante; para os fins didáticos que pretendia, era necessário que o espectador pudesse dialogar com o que estava assistindo. “O teatro que não faz contato com o público não faz sentido nenhum”, dizia (1964:07). $\mathrm{Na}$ análise que Röhl faz da peça didática Ascensão e Queda da Cidade de Mahagonny é possível notar este fato - neste caso, o público-alvo eram operários da Alemanha da metade do século XX:

\footnotetext{
${ }^{8}$ A primeira montagem de Vinegar Tom aconteceu na Inglaterra em 1978 pelo grupo de teatro feministasocialista Monstrous Regiment, que escreveu o texto em colaboração com Caryl Churchill em um processo coletivo de direção.
} 
Nela a música se despe da solenidade própria às óperas e concertos tradicionais, aproximando-se das baladas populares entoadas por cantores de rua, bem como o jazz, das songs dos negros americanos. Vê-se, aqui, a predileção de Brecht pela arte de expressão popular (...). Além de incorporar elementos da tradição popular, a música, na obra brechtiana, tem ainda uma outra função. Como mostra Brecht em suas anotações à ópera em questão, ela não se subordina ao texto, corroborando-o simplesmente, mas se posiciona em relação a ele. (1995:130)

Como no Brasil o espetáculo foi apresentado a um público majoritariamente universitário, jovem e do início do século XXI, para que o efeito de distanciamento e o conseqüente despertar crítico do espectador fossem estimulados e realizados com sucesso, era necessário achar uma linguagem que fosse acessível a este espectador. A banda de rock é um meio satisfatório de se promover este contato com o público. "O rock pressupõe a troca (...), a integração do conjunto ou do vocalista com o público, procurando estimulá-lo a sair de sua convencional passividade perante os fatos" (CHACON, 1985:12). Por isso, pode-se pensar em uma banda de rock como um correspondente contemporâneo da música que Brecht apresentava em suas peças para seu público-alvo.

Apesar de o Teatro Épico prezar por um distanciamento da platéia em relação ao que se passa no palco, para que se possa transmitir uma mensagem de cunho político e, neste caso, feminista, é preciso que haja certo nível de atenção e receptividade por parte do público nos momentos em que a crítica é apresentada. De acordo com as teorias de Brecht, o teatro não deveria envolver o espectador em um raso e hipnótico entretenimento, mas manter sua audiência conectada com a ação em palco era essencial.

\footnotetext{
O público deve ser desencorajado a perder seu distanciamento crítico pela identificação com uma ou mais personagens: o oposto de identificação é a manutenção de uma existência separada daquela do palco pelo fato de estar de fora (...) para manter a audiência relaxada e, mesmo assim, receptiva, para estimular suas faculdades críticas e para fazê-la pensar, o Teatro Épico emprega uma variedade de meios. (ESSLIN, 1995:115, 117).
}

Para tanto, era imprescindível se achar um meio de manter o público conectado com as letras das canções. Por conta disso, optou-se por se iniciar o espetáculo com uma música, e não com uma cena. Foi escolhida a canção Evil Women para a abertura do espetáculo por sua letra que chama a atenção da platéia para o que vai ser mostrado no decorrer da apresentação:

O que quer ver nas telas de cinema?

\footnotetext{
${ }^{9}$ Na versão em português foi intitulada "Dama de Satã"
} 
O que mais deseja ver rolando à noite em sua cama

Sua boca seca, seu coração dispara

Sempre que desperta a cama está molhada

Mulheres nuas povoam sua mente

Perversas criaturas em corpos tão ardentes

Só para seu prazer é que estão no mundo

Uma virgem pra casar, as outras para o sexo imundo. ${ }^{10}$

A música, que no texto original encerra o espetáculo, ao perguntar "Evil women, is that what you want to see $e^{11}$ ?", aponta diretamente ao espectador que acabou de encontrar entretenimento em uma história em que mulheres são enforcadas. O prazer do espectador de hoje em assistir a mulheres sendo condenadas por envolvimento com o diabo sugere que este é o mesmo pensamento de quem as viu, por diversão, queimando em praça pública no século XVII. Neste ponto, os maiores acusados são os homens, pelo seu desejo de ver mulheres objetificadas em telas de cinema e televisões.

O fato de a banda fazer o primeiro contato com o público - intensificado pela letra de tom acusatório - é essencial para que este mantenha sua conexão com as figuras modernas durante o espetáculo. O público, que espera entrar no teatro para assistir a uma história sobre bruxaria na Idade Média, é surpreendido por cinco mulheres trajadas com roupas e maquiagens modernas que brincam com as pessoas e tocam rock. Neste momento, o efeito de distanciamento é realçado, já que a atenção do público não está dividida entre a ação do palco e a música. Apenas a banda é conhecida do público e ela “dá as cartas” do espetáculo, ou seja, diz ao espectador desde o início que ele é parte daquela história e, portanto, deve refletir sobre ela. Desta forma, as intervenções musicais podem ser percebidas como comentários sobre a ação e não como uma mera interrupção no andamento da peça, prendendo a atenção do público.

Um desafio que Churchill deixa aos encenadores de Vinegar Tom é a particularidade das letras das músicas, algumas são sexualmente explícitas, por vezes grosseiras e as palavras não são reprimidas. Elas ligam os eventos da peça a problemáticas feministas do século XX como desejo sexual, envelhecimento, menstruação e menopausa, preconceitos, conflitos psicológicos e obrigações domésticas. A letra da canção Evil Women foi a mais acusada de ofender a platéia e recebeu recorrentes críticas dos espectadores. Apesar disso, como expressa a fala de Gillian Hanna, o Monstrous Regiment estava decidido a não abrir mão delas:

\footnotetext{
${ }^{10}$ Letra adaptada para o português por Schaça a partir da letra de Evil Women.

${ }^{11}$ Em português: "Mulheres más, é isso que você quer ver?"
} 
Nós não queríamos permitir que a audiência perdesse a responsabilidade por assistir a um pedaço interessante de história. Agora, um monte de gente sentiu sua inteligência afrontada por isso. Eles diziam: 'Eu não sei por que essas pessoas têm que pontuar o que elas estão dizendo com estas canções modernas. Nós somos absolutamente capazes de extrair conclusões sobre o mundo de hoje com paralelos históricos'. Na verdade, eu não acredito nisso e, de qualquer forma, nós não podemos correr este risco. Para cada homem inteligente que consegue traçar paralelos, há dezenas de homens que não traçam. Não é que eles não conseguem, é que eles não o fazem (In NEBLETT, 2003:104)

Como na tradução das letras para o português o caráter direto das letras das músicas foi mantido, era necessário achar um mecanismo de fazer com que o público fosse entretido pelas músicas, e não ofendido - pois neste caso se perderia a proposta de levar a audiência a uma autoconsciência que a faz pensar sobre os eventos mostrados no palco. Isto poderia acontecer facilmente como mostra Helene Keyssar:

As músicas (...) funcionam bem em alternar a atenção do horror dos eventos
que estão se desenrolando no palco para a opressão contemporânea que as
mulheres sofrem, mas elas são inapropriadamente didáticas se não forem
executadas propriamente (apud NEBLETT 2003:106).

Para isso, optou-se por criar situações de ironia em relação às músicas por parte da banda. Na música Se Todos Dessem Duro (no original If Everybody Worked As Hard As $M e$ ), por exemplo, canta-se "Ó Sagrada Família, nosso país, é o que é porque nossa família é o que é porque toda mulher obedece" - neste momento, as mulheres da banda usam toucas típicas das mulheres do século XVII (semelhantes às que compõem o figurino de Margery), além de a interpretação estar carregada de deboche e a própria estrutura rítmico-melódica da música acentuar a ironia. A inadequação entre a forma e o conteúdo causa choques na audiência. Quando mulheres roqueiras, jovens e contemporâneas cantam explicitamente sobre mulheres devem obedecer a seus maridos ao mesmo tempo em que usam uma roupa típica de três séculos atrás, o público percebe a desconexão e faz os entendimentos necessários. Rosenfeld mostra como essa idéia se aproxima do teatro brechtiano: "Ao lado da atitude narrativa geral associada à própria estrutura da peça, Brecht emprega, para obter o efeito desejado, particularmente a ironia" (2006:156).

A partir destas técnicas empregadas, o resultado obtido a partir da experiência de Vinegar Tom foi satisfatório à medida que deu nova roupagem a técnicas brechtianas e envolveu o público em um entretenimento composto por autocrítica e entendimento de que a peça não estava apenas ilustrando uma situação do passado, mas que as questões 
ali apresentadas também diziam respeito à sociedade que os envolve. Estas idéias puderam ser comprovadas em momentos como o debate Desmontando Vinegar, em que o público composto por estudantes de Artes Cênicas e professores puderam dar sua opinião sobre o espetáculo. Dentre os comentários, o professor Dr. Edélcio Mostaço declarou: "Muito boa a (...) música composta pela banda. As intervenções da banda são oportunas, bem conduzidas, tirando partido do sentido de interpretação teatral das canções, o que ajuda muito o conjunto". Para a diretora Brígida Miranda, o resultado positivo também pôde ser percebido pelos comentários de mulheres que haviam assistido ao espetáculo, segundo seus comentários no mesmo evento: “A banda seduz a platéia. $O$ fato de serem apenas mulheres tocando cria uma empatia com as espectadoras. Agrada especialmente as mais velhas, pois é um modelo positivo de atitude e subversão". 


\section{Referências Bibliográficas}

CHACON, Paulo. O que é Rock. São Paulo: Nova Cultural/Brasiliense, 1985.

CHURCHILL, Caryl. Vinegar Tom. Londres: Samuel French, Inc, 1982.

ESSLIN, Martin. Brecht: A Choice of Evils. Londres: Methuen, 1995.

FURTADO, Marli. Bertolt Brecht e o Teatro Épico. In: Revista Fragmentos, Volume 05, №. 01. Disponível em:

http://www.periodicos.ufsc.br/index.php/fragmentos/index. Acesso: 15/07/2008.

NEBLETT, Robert. Nobody Sings About It: in defense of the songs in Caryl Churchill's Vinegar Tom. In: HETCH, Stuart (org.). New England Theater Journal. Boston: The New England Theater Conference Press, 2003.

REINELT, Janelle. Beyond Brecht: Britain's New Feminist Drama. In: CASE, Sue-Ellen (org.). Performing Feminisms. Londres: The Johns Hopkins Press, 1990.

RÖHL, Ruth. Ascensão e Queda da Cidade de Mahagonny: Uma Ópera Épica. In: Revista Fragmentos, Volume 05, N. 01. Disponível em:

http://www.periodicos.ufsc.br/index.php/fragmentos/index. Acesso: 15/07/2008.

WILLETT, John. Brecht on Theatre. Nova Iorque: Hill and Wang, 1964. 